\title{
Intertemporal Choice - Toward an Integrative Framework
}

\section{Citation}

Berns, Gregory S., David Laibson, and George Loewenstein. 2007. Intertemporal choice--toward an integrative framework. Trends in Cognitive Sciences 11(11): 482-488.

\section{Published Version}

doi:10.1016/j.tics.2007.08.011

\section{Permanent link}

http://nrs.harvard.edu/urn-3:HUL.InstRepos:4554332

\section{Terms of Use}

This article was downloaded from Harvard University's DASH repository, and is made available under the terms and conditions applicable to Other Posted Material, as set forth at http:// nrs.harvard.edu/urn-3:HUL.InstRepos:dash.current.terms-of-use\#LAA

\section{Share Your Story}

The Harvard community has made this article openly available.

Please share how this access benefits you. Submit a story.

Accessibility 

integrative framework

\section{Gregory S. Berns', David Laibson ${ }^{2}$ and George Loewenstein ${ }^{3}$}

'Department of Psychiatry \& Behavioral Sciences, Emory University School of Medicine, Atlanta, GA 30322, USA

${ }^{2}$ Department of Economics, Harvard University, Cambridge, MA 02138, USA

${ }^{3}$ Department of Social and Decision Sciences, Carnegie Mellon University, Pittsburgh, PA 15213, USA

Corresponding author. Berns,G. (gberns@emory.edu), Laibson, D. (dlaibson@harvard.edu) and Loewenstein, G. (g120@andrew.cmu.edu).

\begin{abstract}
Intertemporal choices are decisions with consequences that ${ }_{55}^{54}$ play out over time. These choices range from the prosaic - 56 how much food to eat at a meal - to life-changing decisions about education, marriage, fertility, health behaviors and 58 savings. Intertemporal preferences also affect policy $_{59}$ debates about long-run challenges, such as global warming. 60 Historically, it was assumed that delayed rewards were discounted at a constant rate over time. Recent theoretical 62 and empirical advances from economic, psychological and 63 neuroscience perspectives, however, have revealed a more 64 complex account of how individuals make intertemporal 65 decisions. We review and integrate these advances. We 66 emphasize three different, occasionally competing, 67 mechanisms that are implemented in the brain: 68 representation, anticipation and self-control.
\end{abstract}

Economic, psychological and neuroscientific perspectives on 70 intertemporal choice

Intertemporal choices - decisions with consequences that 72 play out over time - are important and ubiquitous. 73 Decisions about spending, investments, diet, relationships, 74 fertility, crime and education all contain intertemporal75 tradeoffs. In this paper, we discuss interrelated76 perspectives on intertemporal choice from the fields of 77 economics, psychology and neuroscience.

Until recently, the main contribution of economics to79 the study of intertemporal decisions was modeling. For80 nearly 80 years, economists have analyzed intertemporal81 decisions using the discounted utility (DU) model, which82 assumes that people evaluate the pleasures and pains83 resulting from a decision in much the same way that84 financial markets evaluate losses and gains, exponentially85 'discounting' the value of outcomes according to how86 delayed they are in time. DU has been used to describe87 how people actually make intertemporal choices and it has88 been used as a tool for public policy. Policy decisions about89 how much to spend on research and development, health90 and education all depend on the discount rate used to91 analyze the decision. Indeed, recently the discount rateg2 has proven to be a key parameter in the policy debateg3 about global warming [1].

The main contribution of psychology has been to95 identify, through empirical research, psychological96 mechanisms underlying intertemporal choice. For97 example, George Ainslie's research on the structure of time discounting posed the first serious challenge to the DU model - specifically to the assumption that people discount the future exponentially [2,3]. The concept of 'hyperbolic time discounting' (explained below) can be considered the first observed pattern of behavior that is inconsistent with DU - a DU 'anomaly'. Subsequent research by both psychologists and economists has identified a wide range of additional anomalies [4-12]. Economists have responded to these findings by constructing new models of intertemporal choice, which incorporate psychological insights, to explain otherwise anomalous patterns of economic behavior [13].

Neuroscience is the most recent entrant into what was already a rich interdisciplinary mix of research. Although still in its infancy, neuroscience research on intertemporal choice has led to an enhanced understanding of how intertemporal choices might be implemented in the brain [14-17], and, as we document, has already begun to inform economic modeling and to provide new clues about productive empirical and theoretical avenues for future research.

\section{Time discounting}

The great strengths of the DU model are its simplicity and generality. DU is easy to apply mathematically to any kind of intertemporal choice. According to DU, intertemporal choices are no different from any other type of choices except that some consequences are delayed, and hence must be anticipated and discounted (i.e. reweighted to take account of delay). Much of the research on intertemporal choice has, therefore, focused on the degree to which people anticipate and discount future events.

Numerous experiments in animals, notably rats and pigeons, have shown that under operant conditioning paradigms, the effectiveness of a reinforcer diminishes the further in time it is delayed [18]. In pigeons, for instance, the reinforcement value of three units of reward available in $11 \mathrm{~s}$ is approximately equal to the reinforcement value of eight units of reward available after $20 \mathrm{~s}$ [19]. The traditional model of intertemporal choice uses 'exponential discounting', in which a reward of magnitude $x$ occurring at some time $t$ in the future is worth $\delta x$, where $\delta \leq 1$ is a fixed constant (the discount factor). In other words, the value of the reward decays by the same proportion for each minute that its occurrence is delayed. Figure 1 plots 
three different discount functions, including an61 exponential function with $\delta=0.95$.

However, the bulk of the evidence (primarily from rats63 and pigeons) suggests that animals discount the future in64 a non-exponential manner. The most commonly described65 discounting behavior is hyperbolic, which means that66 delayed rewards are discounted by functions that are67 inversely proportional to delay - for example, 1/t or68 generalizations thereof [18-21]. Hyperboloid discount69 functions decay at a more rapid rate in the short run than70 in the long run, so a hyperbolic discounter is more71 impatient when making short-run tradeoffs than when72 making long-run tradeoffs. Figure 1 also plots a73 hyperboloid [7] and a 'quasi-hyperbolic' discount function74 (Box 1) [13,22].

Humans also have been shown to discount the future76 hyperbolically $[7,20]$, and many commentators have77 implicitly or explicitly drawn connections between the patterns of choice displayed by animals and by humans. 78 However, whether the parallel between animals and 89 humans is a matter of analogy or homology is unclear. 81 Most humans care about, or at least are capable of caring about, costs and benefits that extend years or even 82 decades. By contrast, our nearest evolutionary relatives 83 have measured discount functions that fall in value nearly 84 to zero after a delay of about one minute. For example, 85 Stevens et al. report that cotton-top tamarin monkeys are 86 unable to wait more than eight seconds to triple the value 87 of an immediately available food reward [23].

Some researchers have speculated that the difference 89 between humans and other animals lies in our ability to 90 form a mental image of, and care about, delayed outcomes 91 [24], and there is widespread agreement that the 92 prefrontal cortex, which is disproportionately large in 93 humans relative to other species, has an important role in 94 this capability. The first clues about the function of the prefrontal cortex came from people who experienced 96 damage to it, either through accident, stroke or frontal 98 lobotomy [24-26]. Studies have traced the development of 98 self-control capabilities in children to the maturation of prefrontal areas [27], and still other studies hav100 connected criminality and violent out-of-control behavior\$01 to childhood injury to prefrontal regions [28,29]. Human\$02 undoubtedly share with other animals the mechanism\$03 that produce rapid hyperbolic time discounting, but w104 also have the capacity, seemingly enabled by th05 prefrontal cortex, to make decisions that take account of $\mathbf{1 0 6}$ much longer span of time.

All of these pieces of evidence, as well as the commoin08 observance in humans of extremes in apparent regard (0109 disregard) for the future, have led to a perspective that $i \$ 10$ both new and old. According to this perspective, tim\$11 discounting in humans results from the interaction of twb12 systems, one which is capable of anticipating and caring13 about the distant future, and the other which is much14 more oriented toward the present. Empirical support for15 such a perspective comes from a recent study in which16 subjects' brains were scanned while they made choice $\$ 17$ between smaller money amounts that could be received18 earlier and large amounts that could be received later [14119
Some of the choices were between an immediate and a delayed payment, and others were between delayed and even more delayed payments. The researchers found that prefrontal regions were involved in all intertemporal choices (relative to rest) but that the mesolimbic dopamine system and associated regions were involved only in choices with an immediate outcome. Moreover, when immediate payment was one of the options, the relative activation of the two regions (prefrontal or dopamine) was a significant predictor of choice. This research lends support to the idea that hyperbolic time discounting results from the splicing of two systems with different perspectives toward the future, and that the prefrontal cortex has an especially important role in implementing more patient preferences. However, it does not provide definitive evidence of causal relationships, because the data are purely correlational.

\section{Other dimensions of intertemporal choice}

Time discounting might be the most frequently studied aspect of intertemporal choice, but it is only one of several dimensions that come into play. In this section, we discuss three other mechanisms that, prior research suggests, have an especially important role in intertemporal choice: 'anticipation', 'self-control' and 'representation'. Anticipation refers to an individual's propensity to imagine, and experience pleasure and pain in anticipation of, a future event. Self-control refers to the tensions that people experience when they attempt to implement a farsighted decision in the presence of immediate temptation. Representation refers to the way that the brain interprets or frames a set of choices. Representation often happens first in a decision time-line, but we discuss representation last because less is known about this component of intertemporal decision making. Although these mechanisms, in some situations, come into competition with time discounting, in other situations they contribute to it. Indeed, as touched upon above, there is some question of whether these are the mechanisms underlying time discounting.

\section{Anticipation}

The classical economic model of intertemporal choice assumes that choices have no utility consequences other than the consumption events that result from those choices. For example, the pleasure of a decadent meal is assumed to arise from the meal itself and not the awareness, before the event, that it will take place. In practice, however, when a plan is made in advance - for instance a dinner reservation - there is a waiting period during which the future outcome is anticipated. Moreover, this period of anticipation might have its own affective consequences for the actor. The period between decision and outcome has received relatively little consideration from economic researchers because economic models typically do not treat purely mental events as intrinsic sources of utility [30].

From a behavioral perspective, however, both animals and humans experience subjective changes in mental state associated with this continuous period of anticipation. When rats are conditioned to associate a neutral stimulus 
1 with a noxious outcome (a loud noise), they enter a state of60

2 physiological arousal between the stimulus and outcome.61

3 The degree of arousal is associated with their tendency to62

4 'startle' in response to the noise. Hence, the startle63

5 response serves as a measure of the degree of learning64

6 that has occurred [31,32]. Humans display similar states65

7 of arousal, which can be indexed by the galvanic skin66

8 conductance response (GSR) [33]. When the anticipation67

9 period is extended, the arousal level can assume complex68

10 forms, including an initial surprise effect when the69

11 individual first becomes aware of the impending outcome70

12 and a ramp-up to the time when the outcome is expected71

to occur $[34,35]$.

The anticipation of an outcome can lead to physiological73 arousal, but does this state of anticipation enter into the74 decision-making process? Under certain circumstances it75 does. Consideration of the anticipation of a particularly76 pleasurable event, such as the promise of a kiss from a77 movie star, or the dread of something painful, such as an78 electric shock, often enters into the decisions that people79 make; for example, causing them to get unpleasant80 outcomes over with quickly to eliminate what otherwise81 would be an aversive period of waiting [36,37], behavior82 that is contrary to the most basic prediction of the DU83 model, assuming that people discount the future. A concise84 explanation of this phenomenon is that anticipation can85 confer utility (or disutility) in, and of, itself. Human86 neuroimaging data demonstrate that activity in regions87 associated with the experience of pain increases in88 anticipation of delayed painful stimuli [38-44], and the89 degree of this anticipatory activity correlates with the90 degree to which an individual chooses to expedite91 unpleasant outcomes [36].

Anticipatory responses to appetitive stimuli are also93 common in neural systems, although these tend to be in94 different regions than for aversive stimuli. Anticipatory95 activity in the ventral striatum and orbitofrontal cortex96 has been associated with the prospect of receiving a97 financial windfall [45-47], beautiful faces [48] and98 pleasant-tasting drinks [49-51]. Because of the relatively99 short interval between the cue and the outcome in thes\$00 experiments, it is difficult to ascertain whether th101 activity is in response to the initial cue or the waiting02 period.

\section{Self-control}

\section{3}

104

It is often difficult to wait for a delayed reward when ain05 immediately gratifying alternative is available. For06 instance, quitting smoking is difficult because cigarette $\$ 07$ are available at every news-stand and drug store08 Situations such as this can lead to 'preference reversals1,09 wherein people initially decide to take a far-sighted cours\$10 of action - quitting smoking - but subsequently succumb11 to temptation [20]. Preference reversals are observabli12 phenomena that point to the weaknesses of standard DU13 theory, and they occur in a wide variety of circumstancel14 Although it is possible, as we shall see, to modify th₹15 discount function in a way that explains preferenc\$16 reversals, the core mechanism might be generated by17 phenomena other than the discount function.
Successful implementation of a far-sighted plan of behavior, such as ending a bad habit, thus involves at least two distinct components. First, the individual needs to make an initial far-sighted decision, which is likely to depend on the ability to anticipate future consequences. Second, she needs to resist short-run temptations, which will undermine her ability to implement that decision. Any successful model of intertemporal choice should incorporate features that accurately describe the tug of war between long-run ('virtuous') intentions and short-run temptations.

As a benchmark, the DU model fails this descriptive challenge. As Samuelson [52] noted, the DU model (with exponential discounting) implies that resolutions once made are never broken. Economists refer to this property as dynamic consistency. Anyone who follows the exponential discounting model will be dynamically consistent - they will never change their state-contingent preferences. Plans or preferences made for the future will be the same as decisions executed at the moment of action. In this framework, resolutions to quit smoking or stick to a diet are always carried out (unless new decision-relevant information arrives).

Real people don't have such exquisite self-command $[20,53]$. Most people experience preference reversals: plans made at one date are broken at some later date. For instance, estimates of relapse rates exceed $50 \%$ during the first year after quitting smoking. Many other types of behavior illustrate this tendency to backslide, including credit card spending, exercise and nutrition [54-56]. Beginning with the groundbreaking work of Ainslie [2,20], these types of effects have been integrated into models of time discounting.

The exponential discounting model counterfactually rules out preference reversals. However, any other discounting behavior has the potential to generate preference reversals, which economists refer to as dynamic inconsistency. This potential was first discussed by Samuelson [52] and then developed by others [22,57]. Most research has focused on the class of hyperbolic $[2,7]$ and quasi-hyperbolic discount functions [13], which predict that agents will make patient plans and then break them at the moment of execution (Box 1).

\section{Representation}

Economic analysis assumes that how a choice is represented is an objective matter. But, in fact, it is possible to mentally represent the same situation in a variety of different ways [82]. People use a wide range of choice heuristics to make the decisions they face and which heuristics come into play depends crucially on how they construe these decisions [83,84]. As a result, differences in context or in the way that a decision is 'framed' or cognitively construed can have an impact on the intertemporal tradeoffs that people make.

A child's ability to delay gratification depends on the manner in which the child is instructed to mentally represent a reward $[9,85]$. When given a choice between an immediate single pretzel or two delayed pretzels, children were more likely to wait if instructed to represent the pretzel in pallid or unappealing terms - for instance, 
1 as 'little brown logs' - than if they were to represent the61

2 pretzel in consumatory terms - 'yummy, tasty'. In62 3 research with adults, Wilson and Daly [86] found that63 4 showing male subjects photographs of attractive females64 5 raises the male subjects' monetary discount rates. Wilson65 6 and Daly's results show that reproductively salient stimuli66 7 change the way that individuals evaluate time-dated67 8 monetary rewards, possibly by creating a general sense of68 9 urgency or by generating emotional arousal, which69 10 increases the relative strength of the impatient affective70 11 reward systems.

A variety of studies have shown that framing an72 intertemporal choice in a fashion that draws more73 attention to the need to wait during the delay interval74 tends to produce steeper time discounting - less75 willingness to delay. For example, subjects are much less76 willing to delay gratification when they made a choice that77 was expressed in terms of delay than when the same78 choice was expressed in terms of speed-up or simply as a79 choice between outcomes at two different points in time80 [37]. More recently, several studies have shown that81 people tend to display flatter time discounting when the82 delay interval of an intertemporal choice is presented in83 terms of dates - for example, $x$ today or $y$ on a particular84 date - than when expressed in terms of a delay interval -85 for example, $x$ today or $y$ after a wait of $z$ days (where the86 interval in the two choices is equal) [87].

Given the complexities of many decisions, people often88 simplify the process of decision making by drawing from a 89 toolbox of different choice heuristics - simple rules of 90 choice that dictate what to do in a particular situationg2 [83]. Examples of choice heuristics might include 'pick93 what the last person picked' or 'pick what you picked last 94 time (unless it turned out bad)'. If the representation of 95 the choice affects the selection of choice heuristics, then 96 representation will have an impact on decision making. 98

One important choice heuristic that people seem to99 employ is to choose sequences of outcomes that improv $\mathbf{E 0 0}$ over time - a pattern of choice that effectively results it 01 'negative time preference': subjects prefer to have tha 102 smaller rewards early and the larger rewards laten,04 contrary to what the DU model would predict. Howeven,05 whether a particular intertemporal choice is represente 106 as a sequence, and hence whether this heuristic is applied 107 can depend on relatively subtle factors. In the first 08 demonstration of this point, Prelec and Loewenstein [88]10 asked some subjects to hypothetically choose whether t311 consume a fancy French dinner on the following weeken 12 or on a weekend one month later. Most subjects chose t\$13 have the French dinner on the earlier date. However 14 when the decision was represented as a sequence of twp16 events on fixed dates, where subjects could choose to eat at17 home on one weekend and eat the fancy dinner on th118 other, a majority of subjects now chose to delay the fanc 119 French dinner to the later date. Later research found that 20 the more coherent a sequence was made to seem, the mor 22 probable subjects were to opt for improving sequences [891.23

\section{Conclusion}

The research reviewed above identifies three operation $\$ 26$ that affect intertemporal choice. Anticipation produce $\$ 27$ immediate hedonic consequences, even when the anticipated consumption event is delayed in time. Selfcontrol is used to resist temptations to reverse patient plans. Representations evoke specific choice heuristics that increase or decrease the salience of delayed rewards and make waiting more or less aversive. Any comprehensive account of intertemporal choice should incorporate all of these mechanisms. At the moment, we know little about how these mechanisms interact, which should be a priority for future research. At the most general level, it is important to determine whether the brain has one all-purpose time discounting mechanism or whether the brain draws upon different systems, each with its own occasionally competing time perspective.

Although the new models of intertemporal choice are more realistic than the DU model they are intended to replace, the increased realism has come at the expense of simplicity. Researchers face a familiar conflict between parsimony and realism. We hope that the interactions among economists, psychologists and neuroscientists will identify basic neural mechanisms that explain a wide range of empirical regularities. We believe that models with multiple interacting/competing neural mechanisms represent the most promising research frontier (Box 2). Such models are characterized by at least two classes of neural systems - patient systems that implement cool, analytic preferences and impatient systems that implement hot, affective preferences.

\section{Acknowledgements}

We would like to gratefully acknowledge discussions of these issues with Jonathan Cohen, Keith Ericson and Sam McClure, the input of our editor and three anonymous referees, and the support of the National Institute on Drug Abuse (R01 DA016434 and R01 DA20116 to G.S.B.) and the National Institute on Aging (P30 AG012810 and P01 AG005842. to D.L.).

\section{References}

1 Dasgupta, P. (2006) Comments on the Stern Review's Economics of Climate Change, Cambridge University Press

2 Ainslie, G. (1975) Specious reward: a behavioral theory of impulsiveness. Psychol. Bull. 82, 463-496

3 Rachlin, H. and Green, L. (1972) Commitment, choice and selfcontrol. J. Exp. Anal. Behav. 17, 15-22

4 Green, L. et al. (1981) Preference reversal and self-control: choice as a function of reward amount and delay. Behav. Anal. Lett. 1, 43-51

5 Green, L. et al. (1997) Rate of temporal discounting decreases with amount of reward. Mem. Cognit. 25, 715-723

6 Frederick, S. et al. (2002) Time discounting and time preference: a critical review. J. Econ. Lit. 40, 351-401

7 Loewenstein, G. and Prelec, D. (1992) Anomalies in intertemporal choice: evidence and an interpretation. Q. J. Econ. 107, 573-597

8 Loewenstein, G. and Thaler, R. (1989) Anomalies: intertemporal choice. J. Econ. Perspect. 3, 181-193

9 Metcalfe, J. and Mischel, W. (1999) A hot/cool-system analysis of delay of gratification: dynamics of willpower. Psychol. Rev. 106, 319

10 Mischel, W. et al. (1989) Delay of gratification in children. Science 244, 933-938

11 Rachlin, H. (2000) The Science of Self-Control, Harvard University Press

12 Thaler, R.H. (1981) Some empirical evidence on dynamic inconsistency. Econ. Lett. 8, 201-207

13 Laibson, D.I. (1997) Golden eggs and hyperbolic discounting. Q. J. Econ. 62, 443-477

$14 \quad$ McClure, S.M. et al. (2004) Separate neural systems value immediate and delayed monetary rewards. Science 306, 503-507 
15 Montague, P.R, and Berns, G.S. (2002) Neural74 economics and the biological substrates of valuation. Neuron 36,75 265-284

16 Montague, P.R. et al. (2006) Imaging valuation77 models in human choice. Annu. Rev. Neurosci. 29, 417-448 78 17 Schultz, W. (2006) Behavioral theories and the79 neurophysiology of reward. Annu. Rev. Psychol. 57, 87-115 80 18 Herrnstein, R.J. (1961) Relative and absolute81 strength of response as a function of frequency of reinforcement. J.82 Exp. Anal. Behav. 4, 267-272

19 Mazur, J.E. (1988) Estimation of indifference points84 with an adjusting-delay procedure. J. Exp. Anal. Behav. 49, 37-47 85 20 Ainslie, G. (1992) Picoeconomics: The Strategic86 Interaction of Successive Motivational States Within the Person, 87 Cambridge University Press

21 Chung, S-H. and Herrnstein, R.J. (1967) Choice and89 delay of reinforcement. J. Exp. Anal. Behav. 10, 67-74 90 22 Phelps, E.S. and Pollak, R.A. (1968) On second-best91 national saving and game-equilibrium growth. Rev. Econ. Stud.92 $35,185-199$

23 Stevens, J.R. et al. (2005) The ecology and evolution94 of patience in two New World monkeys. Biol. Lett. 1, 223-226 95 $24 \quad$ Cottle, T.J. and Klineberg, S.L. (1974) The Present of 96 Things Future: Explorations of Time in Human Experience, Free97 Press

25 Damasio, AR. (1994) Descartes' Error: Emotion 99 Reason, and the Human Brain, G.P. Putnam 100 26 Lhermitte, F. (1986) Human autonomy and th101 frontal lobes. 2. Patient behavior in complex and social situation102 - the environmental dependency syndrome. Ann. Neurol. 1903 $335-343$

27 Durston, S. et al. (2002) A neural basis for thl05 development of inhibitory control. Dev. Sci. 5, F9-F16 106 28 Raine, A. et al. (1997) Brain abnormalities 1707 murderers indicated by positron emission tomography. Bio108 Psychiatry 42, 495-508 109 29 Yang, Y. et al. (2005) Volume reduction in prefrontal10 gray matter in unsuccessful criminal psychopaths. Biol. Psychiat 11 57, 1103-1108 112 30 Loewenstein, G. (2006) Pleasures and pains df13 information. Science 312, 704-706 114 31 Gewirtz, J.C. and Davis, M. (2000) Using Pavloviah15 higher-order conditioning paradigms to investigate the neural16 substrates of emotional learning and memory. Learn. Mem. 117 $257-266$

32 Lang P.J. et al. (2000) Fear and anxiety: animal19 models and human cognitive psychophysiology. J. Affect. Disor 120 $61,137-159$

33 Fredrikson, M. and Ohman, A. (1979) Cardiovascular22 and electrodermal responses conditioned to fear-relevant stimul123 Psychophysiology 16, 1-7

$34 \quad$ Ohman, A. (1974) Orienting reactions, expectancl25 learning, and conditioned responses in electrodermal conditionin 126 with different interstimulus intervals. Biol. Psychol. 1, 189-200 127 $35 \quad$ Björkstrand, P.A. (1975) Electrodermal response128 subject control and delay of aversive stimulation. Biol. Psychol. 129 113-120 130 $36 \quad$ Berns, G.S. et al. (2006) Neurobiological substrates df31 dread. Science 312, 754-758 132 37 Loewenstein, G. (1987) Anticipation and th133 valuation of delayed consumption. Econ. J. 97, 666-684 134 38 Ploghaus, A. et al. (1999) Dissociating pain from itk35 anticipation in the human brain. Science 284, 1979-1981 136 39 Ploghaus, A. et al. (2000) Learning about pain: th137 neural substrate of the prediction error for aversive events. Pro138 Natl. Acad. Sci. U. S. A. 97, 9281-9286 139 40 Porro, C.A. et al. (2002) Does anticipation of pai140 affect cortical nociceptive systems? J. Neurosci. 22, 3206-3214 141 $41 \quad$ Ploghaus, A. et al. (2003) Neural circuitry underlyinf42 pain modulation: expectation, hypnosis, placebo. Trends Cogn. Sc143 $7,197-200$

42 Salomons, T.V. et al. (2004) Perceived controllabilitly5 modulates the neural response to pain. J. Neurosci. 24, 7199-720146
43 Wager, T.D. et al. (2004) Placebo-induced changes in fMRI in the anticipation and experience of pain. Science 303, $1162-1167$

$44 \quad$ Koyama, T. et al. (2005) The subjective experience of pain: where expectations become reality. Proc. Natl. Acad. Sci. U. S. A. $102,12950-12955$

45 Breiter, H.C. et al. (2001) Functional imaging of neural responses to expectancy and experience of monetary gains and losses. Neuron 30, 619-639

46 Delgado, M.R. et al. (2000) Tracking the hemodynamic responses to reward and punishment in the striatum. J Neurophysiol. 84, 3072-3077

$47 \quad$ Knutson, B. et al. (2001) Anticipation of increasing monetary reward selectively recruits nucleus accumbens. J. Neurosci. 21, RC159

$48 \quad$ Aharon, I. et al. (2001) Beautiful faces have variable reward value: fMRI and behavioral evidence. Neuron 32, 537-551

49 Berns, G.S. et al. (2001) Predictability modulates human brain response to reward. J. Neurosci. 21, 2793-2798

50 Pagnoni, G. et al. (2002) Activity in human ventral striatum locked to errors of reward prediction. Nat. Neurosci. 5, 97-98

51 McClure, S.M. et al. (2003) Temporal prediction errors in a passive learning task activate human striatum. Neuron $38,339-346$

52 Samuelson, P.A. (1937) A note on measurement of utility. Rev. Econ. Stud. 4, 155-161

53 Schelling, T.C. (1984) Choice and Consequence, Harvard University Press

54 Della Vigna, S. and Malmendier, U. (2006) Paying not to go to the gym. Am. Econ. Rev. 96, 694-719

55 Shui, H. and Ausubel, L.M. (2004) Time Inconsistency in the Credit Card Market, Mimeo

56 Read, D. and van Leeuwen, B. (1998) Predicting hunger: the effects of appetite and delay on choice. Organ. Behav. Hum. Decis. Process. 76, 189-205

57 Strotz, R.H. (1956) Myopia and inconsistency in dynamic utility maximization. Rev. Econ. Stud. 23, 165-180

58 Akerlof, G.A. (1991) Procrastination and obedience. Am. Econ. Rev. 81, 1-19

59 O'Donoghue, T. and Rabin, M. (1999) Doing it now or later. Am. Econ. Rev. 89, 103-124

60 Angeletos, G-M. et al. (2001) The hyperbolic consumption model: calibration, simulation, and empirical evaluation. J. Econ. Perspect. 15, 47-68

61 Giordano, L.A. et al. (2002) Mild opioid deprivation increases the degree that opioid-dependent outpatients discount delayed heroin and money. Psychopharmacology (Berl.) 163, 174182

62 Mitchell, S.H. (2004) Effects of short-term nicotine deprivation on decision-making: delay, uncertainty and effort discounting. Nicotine Tob. Res. 6, 819-828

63 Field, M. et al. (2006) Delay discounting and the behavioural economics of cigarette purchases in smokers: the effects of nicotine deprivation. Psychopharmacology (Berl.) 186, $255-263$

64 Baumeister, R.F. and Heatherton, T.F. (1996) Selfregulation failure: an overview. Psychol. Inq. 7, 1-15

65 Loewenstein, G. (1996) Out of control: visceral influences on behavior. Organ. Behav. Hum. Decis. Process. 65, $272-292$

66 Bernheim, B.D. and Rangel, A. (2004) Addiction and cue-triggered decision processes. Am. Econ. Rev. 94, 1558-1590 67 Pavlov, I.P. (1927) Conditioned Reflexes, Oxford University Press

68 Siegel, S. (1979) The role of conditioning in drug tolerance and addiction. In Psychopathology in Animals: Research and Treatment Implications (Keehn, J.D., ed.), pp. 143-168, Academic Press

69 Laibson, D.I. (2001) A cue-theory of consumption. Q. J. Econ. 66, 81-120

$70 \quad$ Bonson, K.R. et al. (2002) Neural systems and cueinduced cocaine craving. Neuropsychopharmacology 26, 376-386 
71 Brody, A.L. et al. (2002) Brain metabolic changes26 during cigarette craving. Arch. Gen. Psychiatry 59, 1162-1172 27 72 Garavan, H. et al. (2000) Cue-induced cocaine28 craving: neuroanatomical specificity for drug users and drug29 stimuli. Am. J. Psychiatry 157, 1789-1798 30 73 George, M.S. et al. (2001) Activation of prefrontal31 cortex and anterior thalamus in alcoholic subjects on exposure to32 alcohol-specific cues. Arch. Gen. Psychiatry 58, 345-352 33 $74 \quad$ Grant, S. et al. (1996) Activation of memory circuits34 during cue-elicited cocaine craving. Proc. Natl. Acad. Sci. U. S. A.35 $93,12040-12045$

$75 \quad$ Kilts, C.D. et al. (2001) Neural activity related to37 drug craving in cocaine addiction. Arch. Gen. Psychiatry 58, 334-38

76 Fudenberg, D. and Levine, D. (2006) A dual self40 model of impulse control. Am. Econ. Rev. 96, 1449-1476 41 77 Thaler, R.H. and Shefrin, H.M. (1981) An economic42 theory of self-control. J. Polit. Econ. 89, 392-406 43 $78 \quad$ Gul, F. and Pesendorfer, W. (2001) Temptation and44 self-control. Econometrica 69, 1403-1435 45 $79 \quad$ Carter, C.S. et al. (1998) Anterior cingulate cortex,46 error detection and the on-line monitoring of performance. Science 47 280, 747-749

$80 \quad$ Botvinick, M.M. et al. (2001) Conflict monitoring and49 cognitive control. Psychol. Rev 108, 624-652 50
81 Aron, A.R. et al. (2004) Inhibition and the right inferior frontal cortex. Trends Cogn. Sci. 8, 170-177

82 Kahneman, D. et al. (1982) Judgment under Uncertainty: Heuristics and Biases, Cambridge University Press 83 Gigerenzer, G. and Todd, P.M. (1999) Simple Heuristics that Make us Smart, Oxford University Press 84 Gilovich, T. et al. (2002) Heuristics and Biases: The Psychology of Intuitive Judgment, Cambridge University Press 85 Mischel, W. and Underwood, B. (1974) Instrumental ideation in delay of gratification. Child Dev. 45, 1083-1088 86 Wilson, M. and Daly, M. (2004) Do pretty women inspire men to discount the future? Proc. R. Soc. Lond. B. Biol. Sci. 271(Supplement), 177-179

87 Read, D. et al. (2005) Four score and seven years from now: the "date/delay effect" in temporal discounting. Manage. Sci. 51, 1326-1335

88 Prelec, D. and Loewenstein, G. (1993) Preferences for sequences of outcomes. Psychol. Rev. 100, 91-108

89 Ariely, D. and Carmon, Z. (2000) Gestalt characteristics of experiences: the defining features of summarized events. J. Behav. Decis. Making 13, 191-201

90 McClure, S.M. et al. (2007) Time discounting for primary rewards. J. Neurosci. 27, 5796-5804

$91 \quad$ Glimcher, P. et al. (2007) Neuroeconomic studies of impulsivity: now or just as soon as possible? Am. Econ. Rev. 97, $142-147$

\section{Box 1. Modeling preference reversals}

Standard economic theory assumes that individuals (agents) have preferences that are stable through time. In this context a preference refers to a rank ordering of outcomes, or choices, that an individual makes. For example, a person might be said to prefer tea over coffee. However, actions speak louder than words and simply professing such a preference is no guarantee that, given a choice, such an individual would actually choose tea. Because of the hidden nature of preferences, eliciting choices (e.g. through forced-choice or willingness-to-pay) is the only reliable way to measure preferences. Even so, individuals often exhibit reversals in their apparent preferences when it comes to delayed outcomes. Dieting, for example, often falls into this trap of preference reversals. An individual makes a New Year's resolution to lose weight (a temporally remote outcome), but when confronted with the deliciousness of food, changes his mind (a temporally immediate outcome). Such preference reversals can be modeled in terms of a non-exponential discount function. Assume that an economic agent has a quasi-hyperbolic discount function: $1, \beta \cdot \delta, \beta \cdot \delta^{2}, \beta \cdot \delta^{3}, \ldots$. (Figure 1). In general, this discount function is parameterized with $0<\beta<1$ and $0<\delta<1$, but to simplify the illustrative example, set $\beta=1 / 2$ and $\delta=1$, so the discount function takes the form $1,1 / 2,1 / 2,1 / 2, \ldots .$. Immediate payoffs have a weight of one and all future payoffs have a weight of $1 / 2$. Assume that an investment activity has an immediate cost of four and a delayed benefit of six. When the investment opportunity is distant in time, the agent plans to undertake the investment because $1 / 2(-4)+1 / 2(6)=1$. However, when the moment of action arises, the agent changes her mind because $1(-4)+1 / 2(6)=-1$.

If agents anticipate such preference reversals [57], they might find ways to commit themselves in advance - for instance, scheduling an appointment to exercise with a trainer or putting their saving into illiquid accounts [13]. If agents fail to anticipate their preference reversals, they might engage in patently self-defeating behaviors, such as perpetually paying monthly dues at a gym that they never attend [54] or, more generally, procrastinating $[58,59]$.

The predictions of the basic hyperbolic discounting model have been experimentally and empirically validated [20,60]. But the basic hyperbolic discount function provides only a partial account of intertemporal preferences [6]. Most importantly, temporal immediacy of rewards is only one of many factors that seem to produce impulsivity. Other factors include sensory proximity - the sight, sound, smell or touch of a desired reward - and the activation of drive states, such as hunger, thirst or sexual arousal. Thus, for example, mild opioid deprivation in a population of heroin-addicted outpatients produces greater discounting of monetary rewards [61]. Likewise, nicotine deprivation among smokers also produces greater monetary discounting [62,63]. People often lose control in the 'heat of the moment' or when willpower is depleted [64].

Although preference reversals are often attributed to hyperbolic time discounting, they can also result from other mechanisms (which themselves, in some cases, can help to explain hyperbolic time discounting). Three (overlapping) categories of mechanisms are visceral influences, cue-contingent influences and temptation preferences.

Visceral influences are associated with emotion and affect, and are directly related to changes in drive state. Visceral preferences are generated by immediate biological imperatives - for instance, thirst, hunger, sexual arousal, exhaustion, pain, the need to physically dominate an opponent, or fear for physical safety. Loewenstein has argued that visceral needs often overwhelm other goals and produce short-sighted behavior [65]. This assumption has also been adopted in a two-state decision-making model [66]. In the cold state, the decision-maker is guided by forward-looking rational deliberations. In the hot state, the decision-maker is completely controlled by her myopic visceral needs. Hence, highly impatient behavior would be associated with time periods in which the visceral preferences are dominant, explaining many addictive behaviors, including excess use of an addictive substance and relapse after detoxification.

Cue-contingent preferences have been studied since Pavlov's feeding experiments [67]. Cue-contingent preferences are formed when a neutral stimulus is repeatedly paired with a non-neutral stimulus, such as a consumption event. The end result is a change in drive state, even though the eliciting stimulus was, at one point, neutral. For instance, a heroin user might come to associate the visual stimuli of a certain 
environment with ingestion of heroin. Such pairings might be strong enough to elicit cue-contingent drug cravings and cue-contingent tolerance, so that the user's desire to take heroin becomes much stronger when the cues are present [68]. Cue-contingent cravings might produce preference reversals, transitory efforts to achieve immediate gratification, and forward-looking efforts to modify cue exposure $[65,66,69]$. Indeed, several brain-imaging experiments have demonstrated the powerful effect of showing pictures of drug-related paraphernalia to people who are addicted to these substances [70-75]. Although craving, in and of itself, does not represent a breakdown in self-control, it does represent an emotional state that places the individual at risk for a preference reversal. The biological substrates of craving, however, are complex and recruit a wide range of circuits in the brain that include memory regions such as the hippocampus, executive control regions in the prefrontal cortex, and visceral regions such as the insula. However, no single brain region has been demonstrated to be singularly responsible for self-control. Instead, multiple systems process different psychological dimensions of competing preferences.

Temptation preferences arise in two-system models and are another way of describing the temporal immediacy effect of rewards by invoking the cost of self-control [66,76-78]. Rather than postulating a non-exponential discount function, temptation preferences are typically modeled as a drive for immediate gratification, which can be cognitively overridden with some utility cost generated by mental effort (selfcontrol). In the models cited here, the cost is associated with the degree to which the impatient preference is violated. The end result, however, is the same as a non-exponential discount function. For example, imagine that an agent has a craving to eat a (full) bowl of ice cream sitting in front of him, but allows himself to eat only some fraction of that bowl. Temptation models assume that the cost of temptation is falling in the amount that the agent eats. If the agent eats nothing, then temptation costs are maximal. If the agent eats the whole bowl, then temptation costs are zero. Temptation preferences are one way of formally modeling the interaction between the patient (cortical) system and the impatient (mesolimbic dopamine reward related) system. Little is known about the nature of the interaction of these two putative systems, but one brain region, the anterior cingulate cortex (ACC), is thought to have a role in mediating the conflict between competing actions [79,80]. The exertion of self-control requires the suppression of either cravings or temptations, which are the types of competing responses that the ACC modulates. Another region, the inferior prefrontal cortex, seems to be involved in achieving self-control by inhibiting one of these responses [81]. Importantly, how the ACC processes these conflicts and how the inferior prefrontal cortex inhibits one or another depends on the context in which these temptations occur, which leads to the third aspect of intertemporal choice: representation.

\section{Box 2. Directions for future research}

How can neurobiological data be used to develop and test models of intertemporal choice? In the past, the tautology of choice and preference has excluded analysis of neurobiological mechanisms. In recent years, a growing body of data based on brain imaging is enabling researchers to link intertemporal decisions to neural activation patterns, producing both new empirical regularities and new controversies [14,90,91]. The challenge will be to marry neurobiological descriptions with theoretical ones.

Can a single model account for the large range of timescales over which intertemporal choices are made? Such choices range from intervals of milliseconds to decades. Is there a unifying framework for all such intertemporal choices or do different mechanisms apply at different timescales?

How does the representation of time itself influence intertemporal choice? The representation of time is typically assessed in a retrospective manner (i.e. how much time has passed). Intertemporal choices are fundamentally prospective. How does the representation of the past affect the representation of the future?

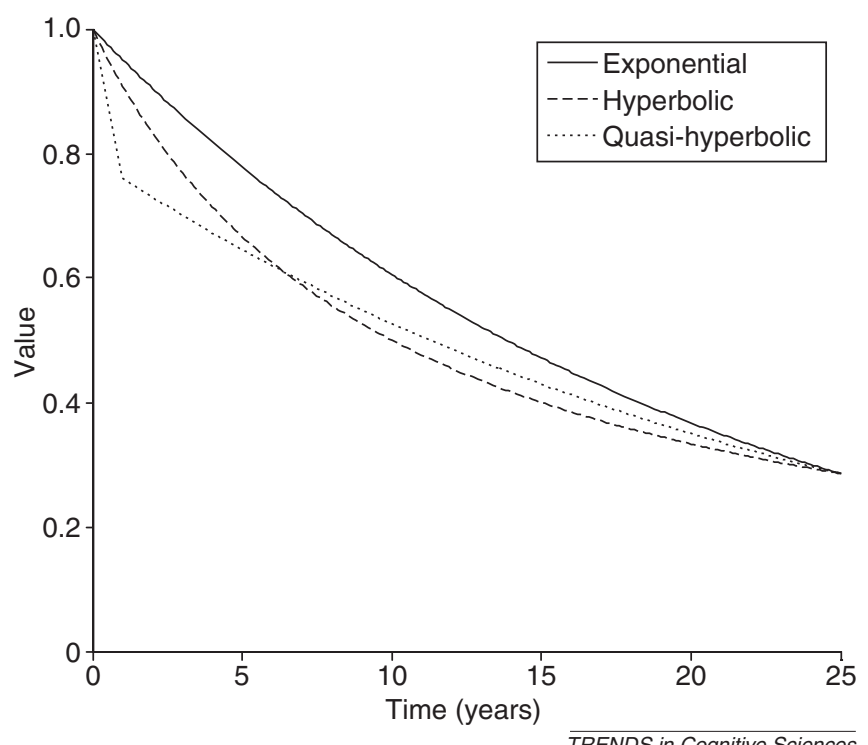

Figure 1. Discount functions. Exponential discounting assumes a constant rate of discounting, e.g. $\delta$ where $\delta$ is the discount rate (here, $\delta=0.95$ ). Hyperbolic discounting is generally greater for short time periods than long periods, and can be described by a function of the form $1 /(K * t+1)$. Here, $K=0.1$. Quasi-hyperbolic discounting is a piecewise function that follows a form similar to exponential discounting after the first discount period (i.e. the first year): $1, \beta \cdot \delta, \beta \cdot \delta^{2}, \ldots, \beta \cdot \delta$. Here, $\beta=$ 0.792 and $\delta=0.96$ ) 